\title{
Value-Added Products from Urea Glycerolysis Using a Heterogeneous Biosolids-Based Catalyst
}

\author{
Mattia Bartoli, Chengyong Zhu, Michael Chae and David C. Bressler* \\ Department of Agricultural, Food and Nutritional Science, University of Alberta, 410 Ag/For Building, \\ Edmonton, AB T6G 2P5, Canada; bartoli@ualberta.ca (M.B.); chengyon@ualberta.ca (C.Z.); \\ mchae@ualberta.ca (M.C.) \\ * Correspondence: david.bressler@ualberta.ca; Tel.: +1-780-492-4986
}

Received: 2 August 2018; Accepted: 29 August 2018; Published: 4 September 2018

\begin{abstract}
Although thermal hydrolysis of digested biosolids is an extremely promising strategy for wastewater management, the process economics are prohibitive. Here, a biosolids-based material generated through thermal hydrolysis was used as a catalyst for urea glycerolysis performed under several conditions. The catalytic system showed remarkable activity, reaching conversion values of up to $70.8 \pm 0.9 \%$ after six hours, at $140{ }^{\circ} \mathrm{C}$ using a catalyst/glycerol weight ratio of $9 \%$ and an air stream to remove $\mathrm{NH}_{3}$ formed during the process. Temperature played the most substantial role among reaction parameters; increasing temperature from $100{ }^{\circ} \mathrm{C}$ to $140{ }^{\circ} \mathrm{C}$ improved conversion by $35 \%$ and glycidol selectivity by $22 \%$. Furthermore, the catalyst retained good activity even after the fourth catalytic run (conversion rate of $56.4 \pm 1.3 \%$ ) with only a slight decrease in glycidol selectivity. Thus, the use of a biosolids-based catalyst may facilitate conversion of various glycerol sources (i.e., byproduct streams from biodiesel production) into value-added products such as glycidol, and may also improve the economic feasibility of using thermal hydrolysis for treatment of biosolids.
\end{abstract}

Keywords: biosolids; urea glycerolysis; glycidol; glycerol carbonate; catalyst

\section{Introduction}

Over the last twenty years, the increased accountability of companies with regards to environmental issues has represented a formidable driving force for the development of sustainable industrial processes [1,2]. As a consequence, the production of fuels and chemicals has started to use recycled or renewable feedstocks in place of oil-based raw materials [3,4] in an attempt to improve process sustainability while maintaining performance of traditional commodities. Nowadays, biodiesel is one of the most well-established technologies based on renewable resources [5], and its production has been increasing every year, partly because of government environmental policies [6]. The increase in biodiesel production has made available abundant amounts of glycerol, a byproduct stream that can be used as feedstock for several chemical syntheses [7]. Among them, the production of glycerol carbonate is of key interest, as it could be used for the synthesis of high-performance hyperbranched polymers [8,9].

Glycerol carbonate is typically produced in a two-step process from the carboxylation of ethane or propene oxide and a subsequent reaction with glycerol [10]. A one-step synthesis of glycerol carbonate has also been reported by several authors through reaction of glycerol with supercritical $\mathrm{CO}_{2}[11]$, or using urea [12,13] or other reagents [14]. Urea glycerolysis is an economically attractive procedure because of the low cost of the reagents and higher yields compared with other routes [15]. In addition, during urea glycerolysis, glycerol carbonate can undergo decarboxylation with the formation of glycidol, a highly reactive compound that could potentially replace glycerol carbonate in the production of polymers, leading to higher quality materials [9]. Despite the better performance of glycidol in 
polymer applications, its synthesis is particularly hazardous and environmentally unfriendly as it involves hydrolysis and dehydrochlorination of epichlorohydrin [16].

To improve classical synthetic pathways, several authors have reported new catalytic systems for the selective conversion of glycerol to glycerol carbonate $[17,18]$. However, the synthesis of glycidol has remained challenging and catalytic systems generally lead to the formation of both glycerol carbonate and glycidol $[12,17,19,20]$. Radical decarboxylation of glycerol carbonate is an interesting alternative procedure that could be combined with the urea glycerolysis process because urea undergoes radical heterolytic cleavage at temperatures higher than $130{ }^{\circ} \mathrm{C}$ [21] forming highly reactive species that lead to the degradation of cyclic carbonates [22]. Several catalytic systems were proposed to enhance the urea reactivity during alcoholysis [23], but metal oxides are typically employed because of their low cost, high recyclability, and good catalytic performances [24,25].

For this purpose, a very attractive source of metal salts and metal oxides is represented by biosolids, a byproduct generated during the treatment of municipal wastewater. Several authors reported the use of biosolids and sewage sludge as iron-based catalysts [26,27]. Furthermore, biosolids ashes were used in several catalytic conversions such as switchgrass gasification [28], pyrolysis of industrial wastes [29], and for organic pollutants removal [30].

Recently, our group reported that thermal hydrolysis of biosolids dramatically increased natural settling rates [31]. Although thermal hydrolysis offers an intriguing solution for treatment and disposal of biosolids, the capital and operating costs may be prohibitive to mainstream adoption. Here, we report that the solid residue remaining after thermal hydrolysis of biosolids, which contains a high concentration of metals, particularly metal oxides (i.e., $\mathrm{Fe}_{2} \mathrm{O}_{3}, \mathrm{Al}_{2} \mathrm{O}_{3}, \mathrm{ZnO}, \mathrm{TiO}_{4}$ and silica), acts as a catalyst for conversion of glycerol to value-added products. Finding value for this solid residue may improve the process economics for the thermal hydrolysis of biosolids, making it a more attractive solution for wastewater treatment facilities. In this work, the metal-rich solid residue recovered after thermal hydrolysis of biosolids was successfully used as heterogeneous catalyst for urea glycerolysis. For these experiments, several parameters were investigated: Temperature, time, catalyst loading, urea/glycerol molar ratio, and residual atmosphere. Based on our findings, the solid residue obtained after thermal hydrolysis of biosolids has great potential for enhancing urea glycerolysis.

\section{Results and Discussion}

\subsection{Assessment of the Biosolids-Based Catalyst}

Urea glycerolysis can proceed through two different mechanisms, a radical or a non-radical pathway (Figure 1). The first step of both pathways involves the formation of a urethane intermediate. This compound evolves through an intermolecular esterification into glycerol carbonate. Subsequently, glycerol carbonate could undergo decarboxylation, which results in the formation of glycidol.

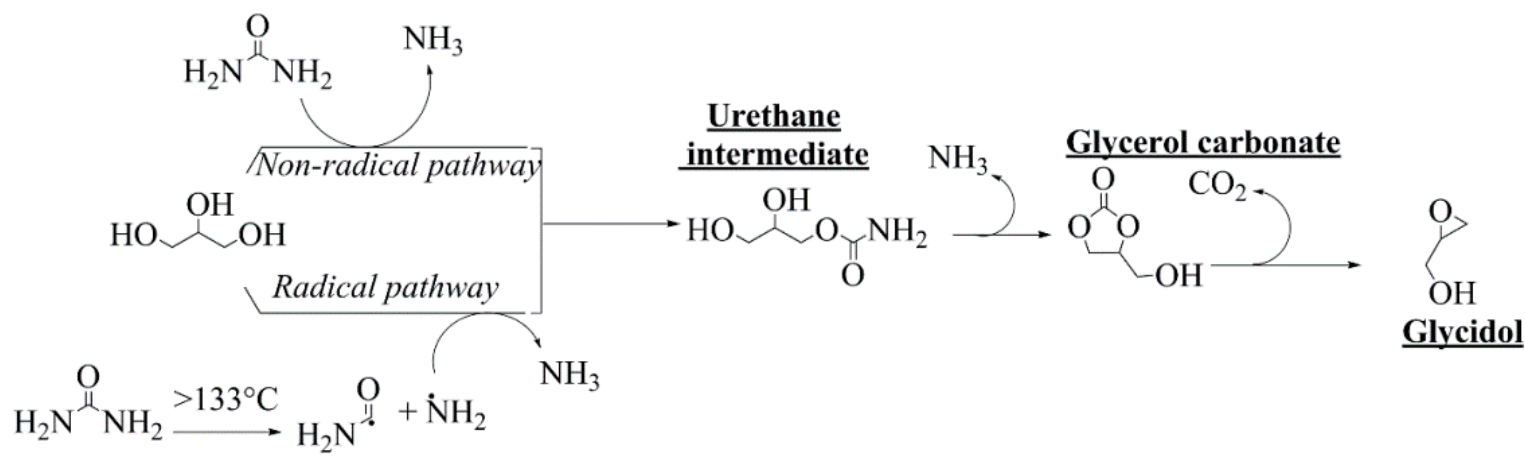

Figure 1. Radical and non-radical reaction pathways for formation of glycerol carbonate and glycidol during urea glycerolysis. 
It has been shown that urea glycerolysis could be performed under catalytic conditions using several metal-based materials containing $\mathrm{Zn}, \mathrm{Al}, \mathrm{Fe}$, Ti, and other metals [32]. The biosolids-based material used as catalyst in these experiments is a dark brown fine powder (Figure 2) and contains an inorganic fraction $(30.3 \pm 0.6 \mathrm{wt} \%)$ that comprises several metal species (Table 1$)$, mainly as oxides, and silica [31].

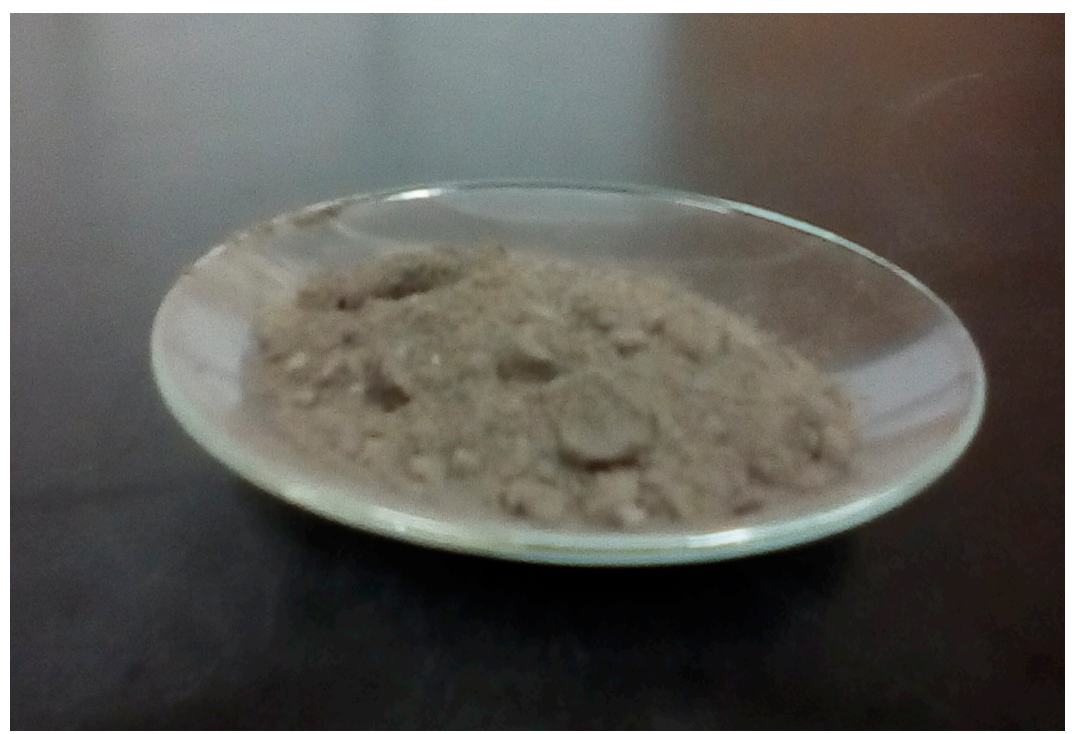

Figure 2. Biosolids-based catalyst as recovered from hydrolysis of biosolid at $280^{\circ} \mathrm{C}$ for $1 \mathrm{~h}$.

Table 1. Concentration of the main metal species in biosolids-based catalysts as determined by Inductively Coupled Plasma-Optical Emission Spectrometer (ICP-OES).

\begin{tabular}{|c|c|c|c|c|c|c|c|c|c|}
\hline & \multicolumn{9}{|c|}{ Concentration of Main Metal Species [mg/g] } \\
\hline & $\mathrm{Cr}$ & $F e$ & $M n$ & $S r$ & $A l$ & $C u$ & $Z n$ & $P b$ & $T i$ \\
\hline Biosolids-based catalyst $^{1}$ & $0.39 \pm 0.02$ & $26 \pm 1$ & $0.58 \pm 0.03$ & $0.37 \pm 0.02$ & $26 \pm 1$ & $0.71 \pm 0.04$ & $1.06 \pm 0.05$ & $0.10 \pm 0.01$ & $3.2 \pm 0.2$ \\
\hline
\end{tabular}

${ }^{1}$ The native biosolids-based catalyst obtained through thermal hydrolysis of biosolids; ${ }^{2} \mathrm{~A}$ recycled biosolids-based catalyst that had been used for four urea glycerolysis reactions.

As reported by Climent et al. [12], the direct interactions between urea, glycerol, and the surface of metal oxides can promote the alcoholysis process. Thus, a heterogeneous catalyst containing a mix of aluminum and zinc oxides, such as the biosolids-based material used in these experiments, has great potential in the production of glycerol carbonate and glycidol. In addition, the biosolids-based catalysts showed a remarkable concentration of surface acidic sites $(5.32 \pm 0.03 \mathrm{mmol} / \mathrm{g})$ that could enhance the decarboxylation of carbonates [33,34]. Finally, as shown by the FT-IR spectrum (Figure 3), carboxylic bands $\left(v_{-\mathrm{OH}}=3400-3300 \mathrm{~cm}^{-1}, v_{-\mathrm{C}=\mathrm{O}}=1800-1700 \mathrm{~cm}^{-1}\right)$ are weaker compared with $v_{-\mathrm{CH}}$ (2900-2800 $\left.\mathrm{cm}^{-1}\right)$ and $v^{-} \mathrm{C}=\mathrm{C}\left(1680-1600 \mathrm{~cm}^{-1}\right)$, supporting the hypothesis that acid sites are mainly inorganic rather than carboxylic functionalities. 


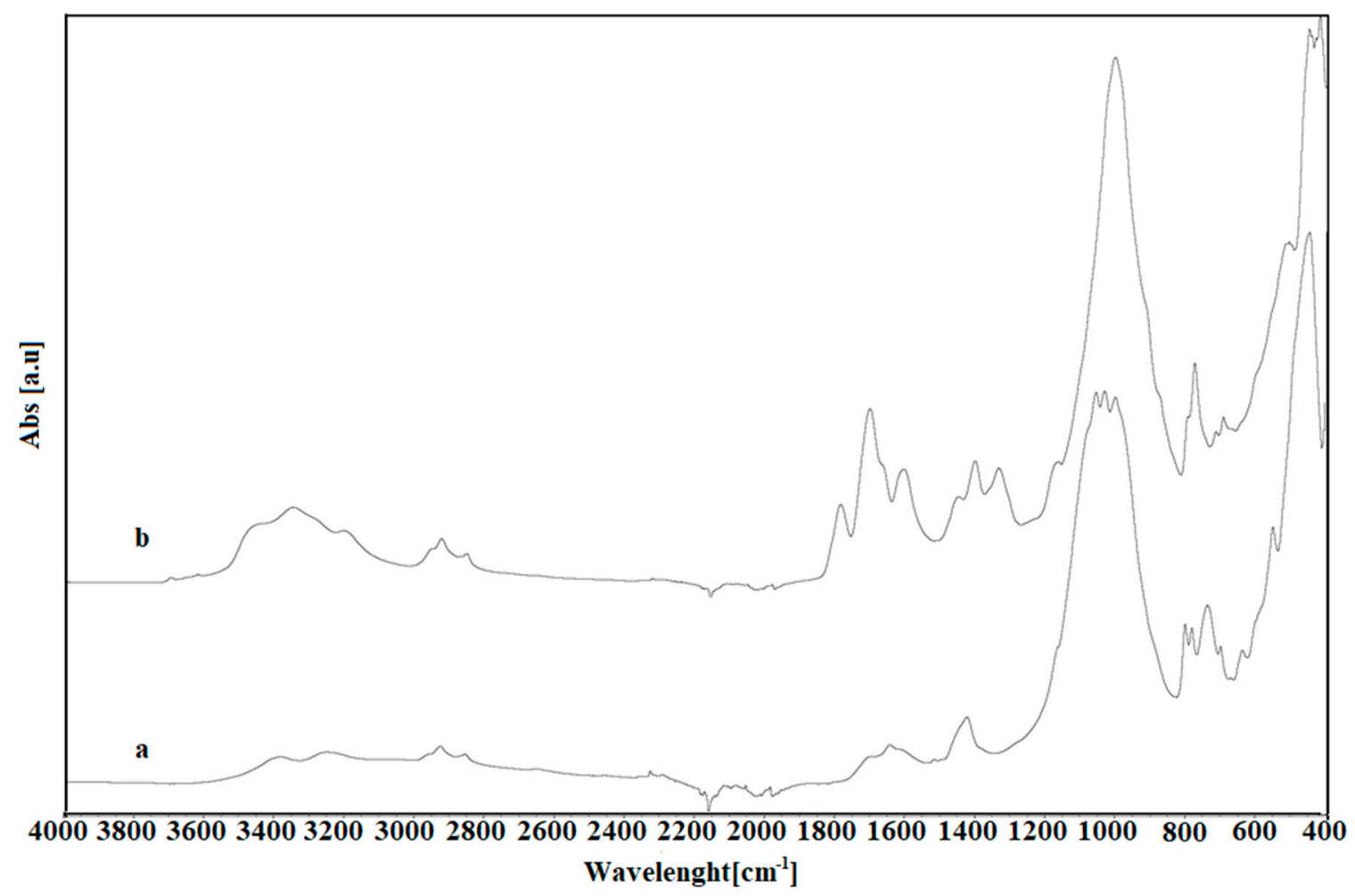

Figure 3. Attenuated total reflection Fourier transform infrared spectroscopy (ATR-FTIR). The spectrum generated in the range of 4000 to $400 \mathrm{~cm}^{-1}$ is shown for the native biosolids-based catalyst (a) and a recycled catalyst that had been used in four catalytic reactions $(\mathbf{b})$.

\subsection{Influence of Catalyst Loading}

The influence of catalyst loading on conversion and selectivity of urea glycerolysis was studied at $140{ }^{\circ} \mathrm{C}$ with a 2:1 molar ratio of urea:glycerol and an air stream to remove $\mathrm{NH}_{3}$ formed during the reaction (Figure 4). The conversion rates achieved with the non-catalytic system were lower than those obtained using any combination of reaction time and catalyst loading, with a maximum conversion value of $46.8 \pm 0.6 \%$ reached after $6 \mathrm{~h}$. Increasing the catalyst loading from 0 to $3 \mathrm{wt} \%$ improved the conversion and after $6 \mathrm{~h}$, a value of $64.1 \pm 0.4 \%$ was achieved. Further improvements in conversion were observed for catalyst loading of $6 \mathrm{wt} \%(66.5 \pm 0.4 \%$ after $6 \mathrm{~h})$ and for $9 \mathrm{wt} \%(69.4 \pm 0.9 \%$ after $6 \mathrm{~h}$ ), but with a catalyst loading of $12 \mathrm{wt} \%$ the conversion values were not significantly different $(p<0.05)$ from those achieved using $9 \mathrm{wt} \%$. The glycidol selectivity for the non-catalytic system was quite high (up to $83.4 \pm 0.6 \%$ after $6 \mathrm{~h}$ ), meanwhile the highest value achieved using the catalytic system was $70.8 \pm 0.4 \%$ after $6 \mathrm{~h}$ using $12 \mathrm{wt} \%$ of catalyst loading.

As reported by Aresta et al. [11], the formation of glycerol carbonate is slower than the decarboxylation process, so in the non-catalytic system at $140{ }^{\circ} \mathrm{C}$, carbonates were degraded to glycidol due to the radical-rich environment granted by the heterolytic splitting of urea. Conversely, the catalytic system increased the reaction rate between reactive species formed by radical degradation of urea and glycerol leading to an increase in conversion and an increase in decarboxylation. Thus, considering the glycidol yields (calculated as the conversion multiplied by selectivity), the catalytic system outperformed the non-catalytic one with maximum glycidol yields of $49.7 \pm 0.9 \%$ (after $6 \mathrm{~h}$ using $9 \mathrm{wt} \%$ of catalyst) and $39.0 \pm 1.0 \%$ (after $6 \mathrm{~h}$ without catalyst), respectively. Based on analysis of variance (ANOVA) outputs, parameters investigated (reaction time and catalyst loading) were statistically significant for both conversion and selectivity values during urea glycerolysis $(p<0.05)$. 
因 $\square 2 \mathrm{~h} \nabla 3 \mathrm{~h} \square 4 \mathrm{~h} \boxminus 5 \mathrm{~h} \boxminus 6 \mathrm{~h}$
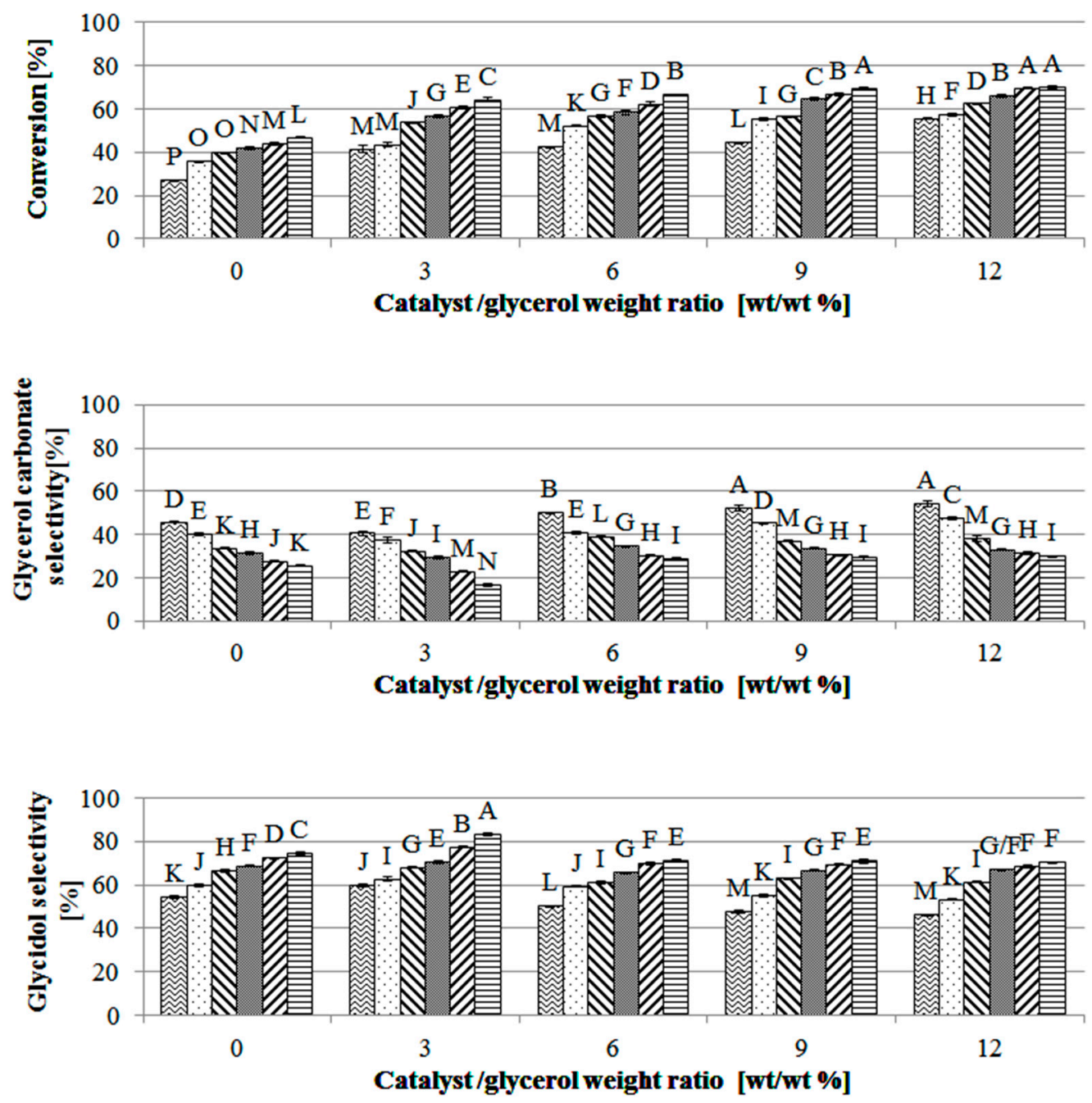

Figure 4. The influence of catalyst loading on the catalytic performance of a biosolids-based catalyst. Reactions were performed at $140{ }^{\circ} \mathrm{C}$, with a 2:1 molar ratio of urea:glycerol, and the use of an air stream to promote the forward reaction. For these experiments, different catalyst:glycerol loading ratios ( $0 \mathrm{wt} \%, 3 \mathrm{wt} \%, 6 \mathrm{wt} \%, 9 \mathrm{wt} \%, 12 \mathrm{wt} \%)$ were examined. The means of triplicate experiments are reported, with the error bars representing standard deviations. Data annotated with different letters are significantly different (confidence level of 95\%).

\subsection{Influence of Temperature}

Temperature is a key parameter for every catalytic conversion and was shown to have a dramatic effect on urea glycerolysis (Figure 5). At $100{ }^{\circ} \mathrm{C}$, the maximum conversion achieved after $6 \mathrm{~h}$ was $44.2 \pm 0.2 \%$, with a drastic decrease to $13.6 \pm 0.9 \%$ for the $1 \mathrm{~h}$ reaction. Increasing the temperature to $120^{\circ} \mathrm{C}$ improved the conversion rate after $1 \mathrm{~h}$ and $2 \mathrm{~h}$, but the conversion values for the remaining reactions $(3 \mathrm{~h}$ to $6 \mathrm{~h})$ were not significantly different $(p<0.05)$ from those achieved at $100^{\circ} \mathrm{C}$ at a given reaction time. A further increase of temperature up to $140{ }^{\circ} \mathrm{C}$ drastically improved the conversion of the reaction. After only $1 \mathrm{~h}$ at $140{ }^{\circ} \mathrm{C}$, the conversion achieved $(44.3 \pm 0.2 \%)$ equaled those obtained at $100{ }^{\circ} \mathrm{C}$ and $120^{\circ} \mathrm{C}$ after $6 \mathrm{~h}$. 

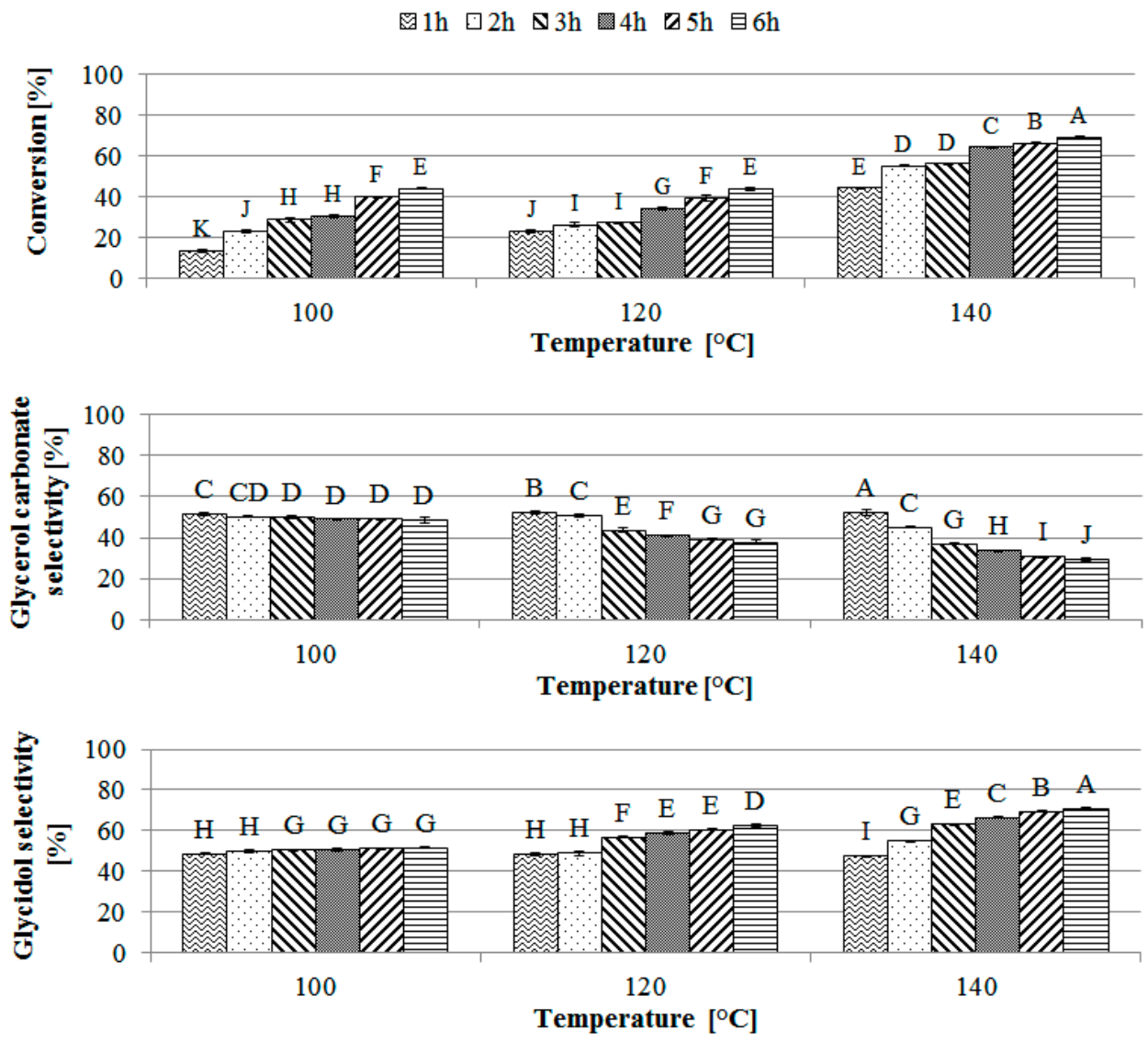

Figure 5. The influence of temperature on the catalytic performance of a biosolids-based catalyst. Reactions were carried out using a catalyst:glycerol ratio of 9\% (wt/wt), a 2:1 molar ratio of urea:glycerol, and an air stream. The conversion and selectivity at three different temperatures were examined: $100^{\circ} \mathrm{C}, 120^{\circ} \mathrm{C}$, and $140^{\circ} \mathrm{C}$. The errors represent the standard deviations calculated according to the values of three experiments. The means of triplicate experiments are reported, with the error bars representing standard deviation. Data annotated with different letters are significantly different (confidence level of 95\%).

According to ANOVA outputs, parameters investigated (reaction time and temperature) were statistically significant for conversion values during urea glycerolysis $(p<0.05)$, and for selectivity only for temperature values below $100^{\circ} \mathrm{C}$. $t$-tests showed the statistical similarity for the selectivity averages at $100{ }^{\circ} \mathrm{C}$. The catalytic system at $100{ }^{\circ} \mathrm{C}$ was not totally selective at any reaction time tested, leading to the formation of an equal amount of glycerol carbonate and glycidol. At $120^{\circ} \mathrm{C}$, moving from $1 \mathrm{~h}$ to 6 $\mathrm{h}$ increased the selectivity for glycidol from $48.2 \pm 0.4 \%$ to $62.7 \pm 0.9 \%$. This trend was clearer at 140 ${ }^{\circ} \mathrm{C}$ with an increase in selectivity from $46.2 \pm 0.2 \%$ after $1 \mathrm{~h}$ to $70.2 \pm 0.4 \%$ after $6 \mathrm{~h}$. Decarboxylation of glycerol carbonate to glycidol is due to the synergistic effect of acidic-basic functionalities on the surface of the catalysts and the radical-rich reaction environment promoted by urea splitting [11]. The contribution of urea splitting was magnified as the temperature was increased to $140{ }^{\circ} \mathrm{C}$, becoming the predominant driving force of the process.

\subsection{Influence of the Molar Ratio of Urea/Glycerol}

The effect of urea/glycerol ratio was also investigated at $140{ }^{\circ} \mathrm{C}$ using a catalyst loading of $9 \mathrm{wt} \%$ and an air stream to facilitate the removal of $\mathrm{NH}_{3}$ formed during the reaction (Figure 6). Decreasing the molar ratio of urea/glycerol from 2:1 to 1:1 led to a significant $(p<0.05)$ decrease in conversion values for each time tested, with a maximum conversion of $59.9 \pm 1.2 \%$ achieved after $6 \mathrm{~h}$. In addition, 
a urea/glycerol molar ratio of 1:1 led to a decrease in the maximum glycidol production (down to $65.7 \pm 0.9 \%$ after $6 \mathrm{~h}$ ), caused by the decreased amount of radical species in the reaction environment. Based on ANOVA outputs, parameters investigated (reaction time and urea/glycerol) were statistically significant for conversion during urea glycerolysis $(p<0.05)$. These results support the hypothesis that the radical heterolytic splitting of urea played a major role in the process at reaction temperatures greater than $140{ }^{\circ} \mathrm{C}$, promoting the radical reaction pathway, instead of the non-radical one.
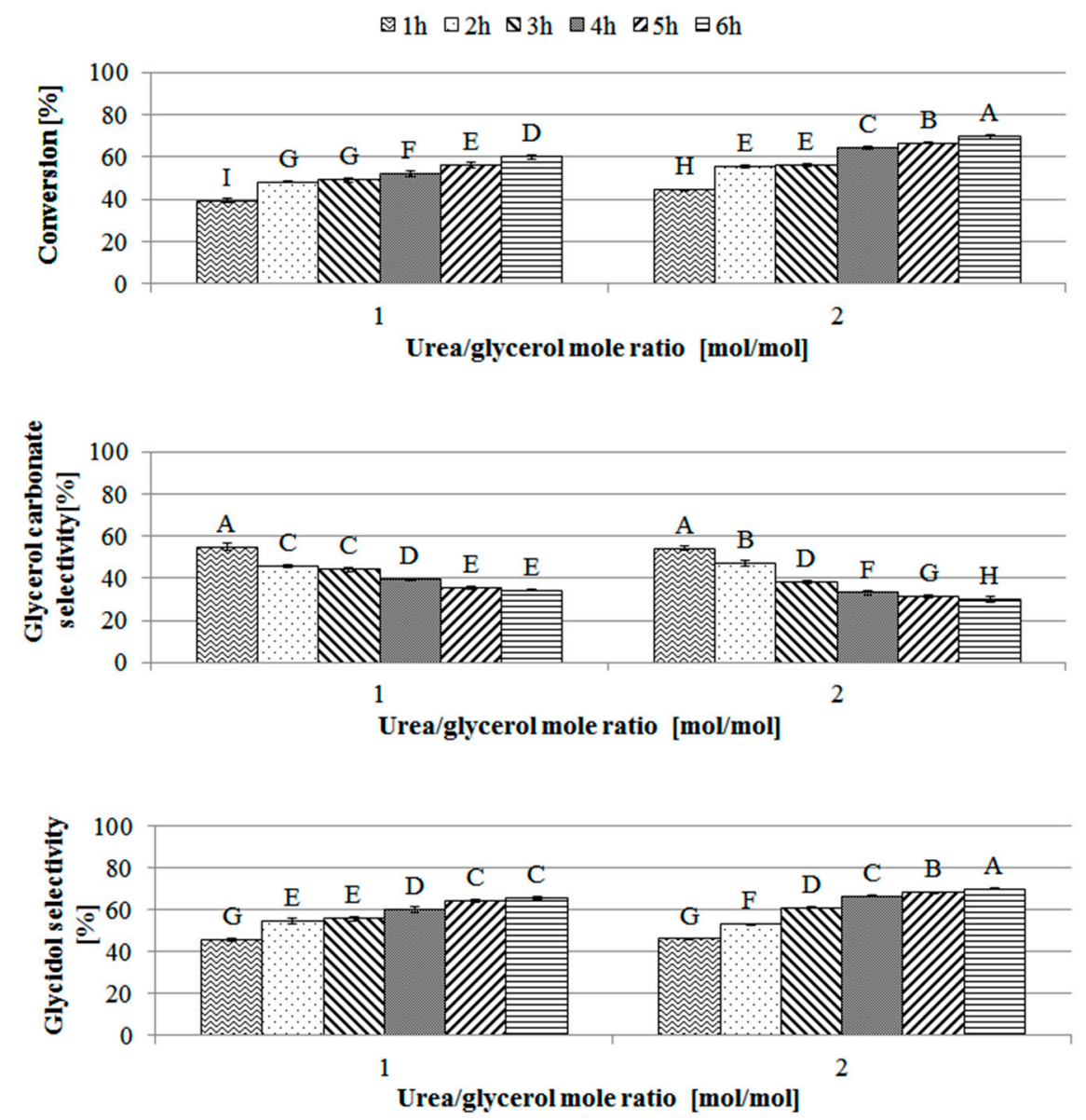

Figure 6. The influence of molar ratio on the catalytic performance of a biosolids-based catalyst. For the reactions shown below, the catalyst:glycerol ratio was maintained at $9 \mathrm{wt} \%$ at a reaction temperature of $140{ }^{\circ} \mathrm{C}$ and using an air stream. To determine the effect of using different urea:glycerol ratios, two molar ratios were employed: 2:1 and 1:1 (mol/mol). The means of triplicate experiments are reported, with the error bars representing standard deviation. Data annotated with different letters are significantly different (confidence level of 95\%).

\subsection{Influence of Residual Atmosphere}

Formation of $\mathrm{NH}_{3}$ as a byproduct during urea alcoholysis is a considerable issue in terms of both the reaction kinetics and the sustainability of the process. In order to remove $\mathrm{NH}_{3}$ from the reaction environment, urea glycerolysis could be carried out using reactive distillation procedures [35], reduced pressure [32], or using a stream of air. In order to remove $\mathrm{NH}_{3}$, three different gas streams (air, $\mathrm{N}_{2}$, $\mathrm{CO}_{2}$ ) were evaluated at $140{ }^{\circ} \mathrm{C}$ using a catalyst loading of $9 \mathrm{wt} \%$ and a 2:1 molar ratio of urea:glycerol (Figure 7). 
$\otimes 1 h \square 2 h \quad \$ 3 h \quad \square h \quad \square 5 h \quad \boxminus 6 h$
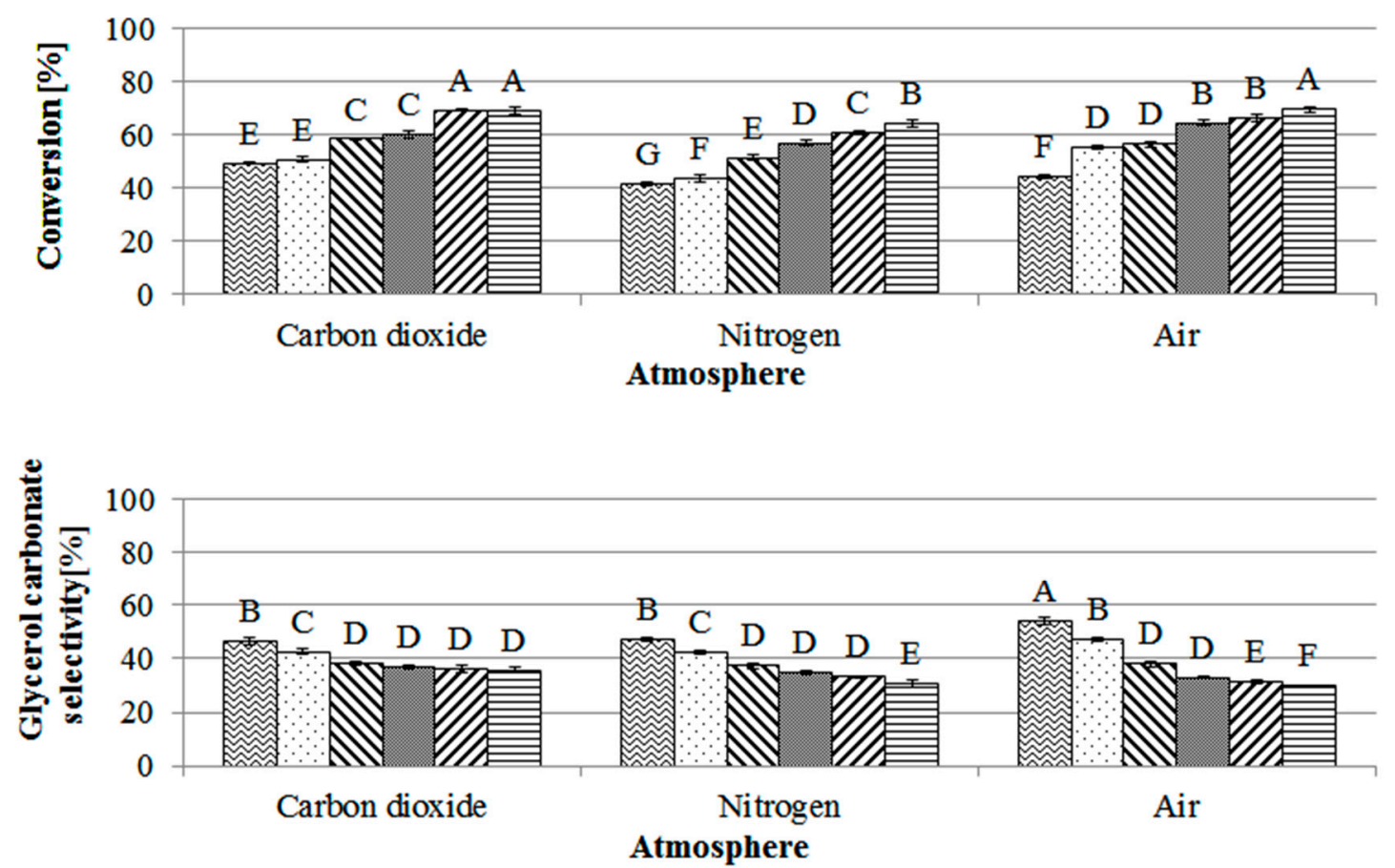

Figure 7. The influence of atmosphere on the catalytic performance of a biosolids-based catalyst. The following reaction conditions were used: A catalyst:glycerol ratio of $9 \mathrm{wt} \%$, a temperature of $140{ }^{\circ} \mathrm{C}$, a 2:1 molar ratio of urea:glycerol, and three different gas streams to remove $\mathrm{NH}_{3}$ formed during the reaction (air, $\mathrm{N}_{2}, \mathrm{CO}_{2}$ ). The errors represent the standard deviations calculated according to the values of three experiments. The means of triplicate experiments are reported, with the error bars representing standard deviation. Data annotated with different letters are significantly different (confidence level of 95\%).

According to ANOVA, parameters investigated (reaction time and residual atmosphere) were both statistically significant and relevant for conversion values during urea glycerolysis, assuming $p<0.05$, but their influence on selectivity values was smaller. Adopting a $\mathrm{N}_{2}$ stream in place of the air stream that was used in the experiments described above did not result in a significant difference in the maximum conversion after $6 \mathrm{~h}$. For the $\mathrm{N}_{2}$ stream, a significant $(p<0.05)$ increase in conversion values was observed as the reaction time was lengthened from $1 \mathrm{~h}$ to $5 \mathrm{~h}$, but no further increase was observed when the reaction time was increased to $6 \mathrm{~h}$. Using $\mathrm{CO}_{2}$, the conversions were generally lower with a maximum conversion of $64.0 \pm 1.2 \%$ achieved after $6 \mathrm{~h}$, which was significantly lower than the values achieved using air or $\mathrm{N}_{2}$ for an equivalent reaction time. Furthermore, the selectivity of glycidol was lower $(35.8 \pm 1.2 \%)$ when $\mathrm{CO}_{2}$ was used as the atmospheric gas, likely because the increase in $\mathrm{CO}_{2}$ partial pressure decreased the rate of decarboxylation of glycerol carbonate. Based on the results shown, the use of an air stream for the removal of $\mathrm{NH}_{3}$ is likely preferred given that it had the highest conversion rate and glycidol selectivity, and is also the cheapest option.

\subsection{Influence of Recycling on Urea Glycerolysis on the Conversion Rate}

Next, we examined whether or not the biosolids-based catalyst could be recycled. The activity of the catalyst was monitored after each of four runs, with each reaction conducted at $140{ }^{\circ} \mathrm{C}$ for $6 \mathrm{~h}$ using a catalyst loading of $9 \mathrm{wt} \%$, a 2:1 molar ratio of urea:glycerol, and a stream of air to remove $\mathrm{NH}_{3}$ formed during the reaction (Figure 8). The activity of the biosolids-based catalyst decreased from $69.4 \pm 0.9 \%$ for the first run to $56.4 \pm 1.3 \%$ for the fourth run. Similarly, the glycidol selectivity dropped from $71.1 \pm 0.7 \%$ to $65.6 \pm 0.9 \%$. The decreased catalyst activity was likely attributable to 
the leaching of metals (Table 1), caused by the formation of soluble metal species as a consequence of reactions between urea-derived radicals and metal surface sites. In addition, chemical modification of the organic fraction of the biosolids-based material was observed through ATR-FTIR analysis of the recycled catalyst recovered after the fourth catalytic run (Figure 2). The chemical modifications could be ascribed to the formation of amino and amido groups (IR bands of $v_{-\mathrm{NH}}$ in the range of $3500-3400 \mathrm{~cm}^{-1}$ and amido $v_{-\mathrm{C}=\mathrm{O}}$ in the range of $1800-1700 \mathrm{~cm}^{-1}$ ) caused by the reaction between the urea-derived radical species and the aromatic organic matrix.

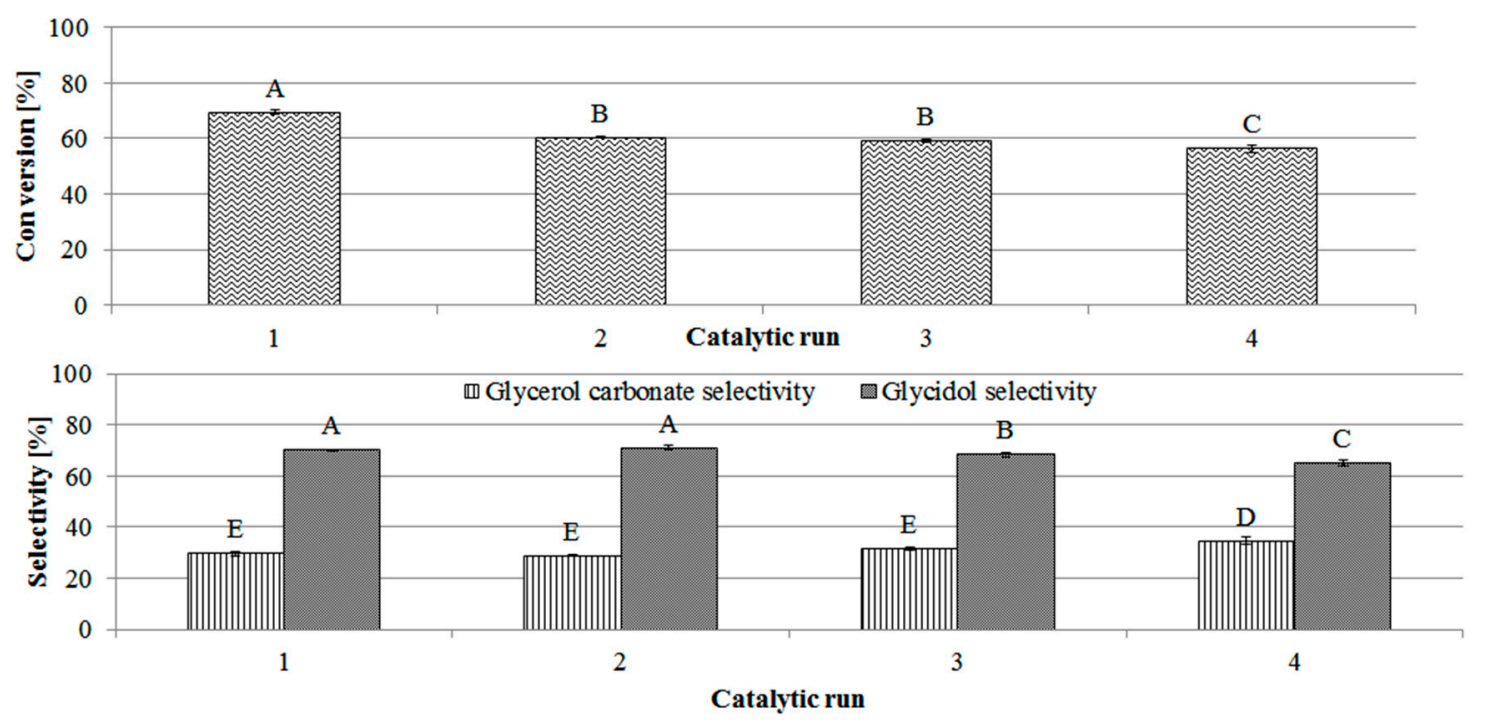

Figure 8. Recyclability of the biosolids-based catalyst. during four catalytic runs (catalyst/glycerol 9 wt $\%, 140{ }^{\circ} \mathrm{C}$, urea/glycerol $2 \mathrm{~mol} / \mathrm{mol}$, air stream, $6 \mathrm{~h}$ ) The errors represent the standard deviations calculated according to the values of three experiments. The means of triplicate experiments are reported, with the error bars representing standard deviation. Data annotated with different letters are significantly different (confidence level of 95\%).

\subsection{Comparison between Biosolids Based Catalysts and Heterogenous Catalysts}

Several materials were studied as catalysts for urea glycerolysis. Among them, zinc-based catalysts play a major role. As reported by several authors [12,36-38], use of different zinc salts induced different conversion and glycerol carbonate selectivity during urea glycerolysis. Zinc-halogen binary salts showed a close relationship between anions and zinc activity with an increase in conversion from $64.3 \%$ using $\mathrm{ZnF}_{2}$ to $81.4 \%$ using $\mathrm{ZnBr}_{2}$ at $150{ }^{\circ} \mathrm{C}$ for $4 \mathrm{~h}$. The increased mobility of bromine with respect to fluorine also affected glycerol carbonate selectivity with an increase from $84.1 \%$ to $97.2 \%$ [36]. Our biosolids-based catalyst is out-performed by zinc salts but it is active $\mathrm{ZnO}$ that likely promotes a conversion of $69.9 \%$ at higher temperature $\left(150{ }^{\circ} \mathrm{C}\right.$ for $\left.4 \mathrm{~h}\right)$ with an inferior selectivity for glycerol carbonate $(68.5 \%)$. Furthermore, our biosolids-based catalyst is comparable with cobalt nanoparticles supported on $\mathrm{ZnO}$ [37], and zinc-tin catalysts [38] that reached conversion around $69 \%$ at $150{ }^{\circ} \mathrm{C}$. Other expensive catalysts such as $\mathrm{Au}$ and Pd nanoparticles [39], ionic liquids [40] or lanthanum oxides [41] could be used achieving conversion up to $84 \%$ and selectivity around $87 \%$, but they require several steps for preparation and high control of reaction conditions. Nevertheless, a key advantage to our biosolids-based catalyst is the fact that it can be generated from a negative-value waste stream using a thermal treatment that has also been shown to drastically improve settling rates [31]. Therefore, thermal hydrolysis of biosolids may simultaneously address a growing problem in the treatment of municipal wastewater, while at the same time generating a value-added heterogeneous catalyst. 


\section{Materials and Methods}

\subsection{Materials}

Tetrahydrofuran (HPLC grade, >99.9\% without stabilizers), methanol (HPLC grade, >99.9\%), urea (98\%), $\mathrm{NaOH}(>99 \%), \mathrm{HCl}(37 \%)$ and methyl nonadecanoate (used as internal standard for gas chromatography) were purchased from Sigma-Aldrich (St. Louis, MO, USA). Glycerol (98\%) and heptane (>99\%) were purchased from Fisher Chemical (Fair Lawn, NJ, USA). Gases (Air, $\mathrm{CO}_{2}, \mathrm{~N}_{2}, \mathrm{H}_{2}$, He) were purchased from Praxair Inc. (Edmonton, AB, Canada).

\subsection{Methods}

\subsubsection{Catalytic Acetylation of Glycerol}

$10 \mathrm{~g}$ of glycerol were put into a single-neck round-bottom flask with urea (urea/glycerol molar ratio $(\mathrm{mol} / \mathrm{mol}$ ) of 2 or 1 ), the biosolids based catalyst (catalyst/glycerol weight ratio (wt/wt) of $12 \%$, $9 \%, 6 \%, 3 \%, 0 \%$ ), which was then connected to a condenser. The reaction mixtures were stirred and heated at different temperatures $\left(100{ }^{\circ} \mathrm{C}, 120^{\circ} \mathrm{C}, 140{ }^{\circ} \mathrm{C}\right)$ for $6 \mathrm{~h}$ with sampling every hour. During the reaction, a stream of air, $\mathrm{N}_{2}$, or $\mathrm{CO}_{2}$ was employed to remove $\mathrm{NH}_{3}$ formed during the process. After $6 \mathrm{~h}$, the reaction mixtures were cooled at room temperature and the catalyst was recovered through centrifugation $(7155 \times g$ for $10 \mathrm{~min})$, washed with acetone three times ( $5 \mathrm{~mL}$ for each wash), dried overnight at $105^{\circ} \mathrm{C}$, and then analyzed. Each test was replicated three times.

\subsubsection{Gas Chromatography and Mass Spectrometry}

$100 \mu \mathrm{L}$ of the crude reaction mixture were diluted with $0.5 \mathrm{~mL}$ of tetrahydrofuran and $0.5 \mathrm{~mL}$ of methanol, with $10 \mathrm{mg}$ of methyl nonadecanoate added as internal standard. The solution was analyzed using a gas chromatograph (6890N; Agilent Technologies, Fort Worth, TX, USA) equipped with an autosampler (Agilent 7683 series; Agilent Technologies, Fort Worth, TX, USA), a flame ionization detector, and a mass spectrometer (Agilent 5975B inert XL EI/CI MSD; Agilent Technologies, Fort Worth, TX, USA). Analyses were carried out by injecting $1 \mu \mathrm{L}$ of the samples onto a DB-5 column $(100 \mathrm{~m} \times 250 \mu \mathrm{m} \times 0.25 \mu \mathrm{m}$; Agilent Technologies, Fort Worth, TX, USA) using the gas chromatographic method described above [42]. The concentration of unreacted glycerol was evaluated using a five-point calibration curve $\left(\mathrm{m}=0.185 \pm 0.02, \mathrm{R}^{2}=0.994\right)$ obtained using methyl nonadecanoate as the internal standard.

\subsubsection{Characterization of Inorganic Content in the Biosolids-Based Catalyst}

The amount of inorganic residue contained in the solid material recovered after thermal hydrolysis of biosolids at $280{ }^{\circ} \mathrm{C}$ for $1 \mathrm{~h}$ was determined through incineration of $5 \mathrm{~g}$ of the sample at $450{ }^{\circ} \mathrm{C}$ for $6 \mathrm{~h}$ using a 48000 Furnace (Barnstead Thermolyne, Dubuque, IA, USA) in accordance with the method developed by Benitez et al. [43]. This test was repeated three times. Compositional analysis of the inorganic content was performed using a Thermo iCAP 6000 series Inductively Coupled Plasma-Optical Emission Spectrometer (ICP-OES; Thermo Fisher Scientific, Madison, WI, USA) at the Natural Resources Analytical Laboratory (Department of Renewable Resources, University of Alberta).

\subsubsection{Quantification of Total Surface Acidic Groups}

The total surface acidic groups present in the biosolids-based catalyst were determined through titration based on the procedure proposed by Boehm [44]. Briefly, $150 \mathrm{mg}$ of catalyst were put in a plastic tube with $50 \mathrm{~mL}$ of $0.05 \mathrm{~N} \mathrm{NaOH}$ and stirred at room temperature for $24 \mathrm{~h}$. Afterwards, the mixture was centrifuged at $7155 \times g$ for $10 \mathrm{~min}$ and the solid was removed. $25 \mathrm{~mL}$ of centrifuged solution were then neutralized with a standard solution of $0.05 \mathrm{~N} \mathrm{HCl}$. The total surface acidic groups were determined as the difference between the mmol of $\mathrm{NaOH} 0.05 \mathrm{~N}$ before and after the titration, which is equivalent to the mmol of $0.05 \mathrm{~N} \mathrm{HCl}$ added. 


\subsubsection{Attenuated Total Reflection Fourier Transform Infrared Spectroscopy}

Attenuated total reflection Fourier transform infrared spectroscopy (ATR-FTIR) analyses were carried out using a Nicolet iS50 (Thermo Fisher Scientific, Madison, WI, USA) in the range of $4000-600 \mathrm{~cm}^{-1}$ with a band of resolution of $2 \mathrm{~cm}^{-1}$. These analyses were performed at the nanoFAB Centre at the University of Alberta.

\subsubsection{Statistical Analysis}

One-way and Two-way ANOVA tests with a significance level of $0.05(p<0.05)$ were carried out using Excel ${ }^{\mathrm{TM}}$ software (Microsoft Corp., Redmond, WA, USA) and the "Data analysis" plug-in.

\section{Conclusions}

The solid recovered after hydrolysis of biosolids at $280^{\circ} \mathrm{C}$ for $1 \mathrm{~h}$ has been successfully employed as a catalyst for urea glycerolysis. It showed a remarkably activity reaching a maximal conversion value of $70.1 \pm 0.5 \%$ and a glycidol selectivity of up to $70.8 \pm 0.9 \%$. Temperature had the greatest impact on the conversion and selectivity, and was likely caused by the elevated heterolytic radical splitting of urea that drastically enhanced the reaction efficiency as the temperature was increased. For the same reason, increasing the molar ratio of urea:glycerol to 2:1 showed better performance compared with values obtained using a ratio of 1:1. Increasing catalyst loading slightly improved the conversion, but did not strongly affected the selectivity. Furthermore, the use of an air or $\mathrm{N}_{2}$ stream to remove $\mathrm{NH}_{3}$ formed during the process was shown to more effective than the use of $\mathrm{CO}_{2}$. The catalyst could be recycled, but a decreased catalytic activity was observed after the fourth catalytic run, though conversion rates were still reasonably high. In future studies, a continuous process (distillation of products and supplemental addition of reagents) will be studied to improve the life of the catalyst. In conclusion, we have proven that the biosolid-based material functions as a reliable catalyst for production of glycidol through a urea glycerolysis reaction, providing potential benefits to both the biodiesel industry and wastewater management facilities.

Author Contributions: Conceptualization, M.B. and D.C.B.; Methodology, M.B.; Formal Analysis, M.B.; Investigation, M.B. and C.Z.; Data Curation, M.B.; Writing-Original Draft Preparation, M.B.; Writing-Review \& Editing, M.C. and D.C.B; Supervision, D.C.B.; Project Administration, M.C. and D.C.B.; Funding Acquisition, M.C. and D.C.B.

Funding: The work described in this research was achieve through generous financial support from the Natural Sciences and Engineering Research Council of Canada (NSERC) [grant number RGPIN 298352-2013], Mitacs Canada [grant number MI MA IT05367], BioFuelNet Canada [grant number NCEBFNC 6F], and our collaborators from Forge Hydrocarbons Inc. who also hosted Mattia Bartoli and Chengyong Zhu as interns.

Acknowledgments: We are also thankful for the support provided throughout the project by the Natural Resources Analytical Laboratory (Chemistry Department, University of Alberta), NanoFab Centre (University of Alberta), the City of Edmonton, EPCOR Water Services Inc., and Suez.

Conflicts of Interest: The funders had no role in the design of the study, in the collection, analyses, or interpretation of data; in the writing of the manuscript. Forge Hydrocarbons Inc. reviewed the manuscript prior to submission strictly to ensure that there was no release of confidential information.

\section{References}

1. Leiserowitz, A.A.; Kates, R.W.; Parris, T.M. Sustainability values, attitudes, and behaviors: A review of multinational and global trends. Annu. Rev. Environ. Resour. 2006, 31, 413-444. [CrossRef]

2. United, N. Johannesburg declaration on sustainable development. In Proceedings of the World Summit on Sustainable Development, Johannesburg, South Africa, 26 August-4 September 2002.

3. Anastas, P.; Eghbali, N. Green chemistry: Principles and practice. Chem. Soc. Rev. 2010, 39, 301-312. [CrossRef] [PubMed]

4. Manzer, L.E. Recent developments in the conversion of biomass to renewable fuels and chemicals. Top. Catal. 2010, 53, 1193-1196. [CrossRef] 
5. Hill, J.; Nelson, E.; Tilman, D.; Polasky, S.; Tiffany, D. Environmental, economic, and energetic costs and benefits of biodiesel and ethanol biofuels. Proc. Natl. Acad. Sci. USA 2006, 103, 11206-11210. [CrossRef] [PubMed]

6. Ryan, L.; Convery, F.; Ferreira, S. Stimulating the use of biofuels in the European Union: Implications for climate change policy. Energy Policy 2006, 34, 3184-3194. [CrossRef]

7. Yang, F.; Hanna, M.A.; Sun, R. Value-added uses for crude glycerol-A byproduct of biodiesel production. Biotechnol. Biofuels 2012, 5, 13. [CrossRef] [PubMed]

8. Clements, J.H. Reactive applications of cyclic alkylene carbonates. Ind. Eng. Chem. Res. 2003, 42, 663-674. [CrossRef]

9. Rokicki, G.; Rakoczy, P.; Parzuchowski, P.; Sobiecki, M. Hyperbranched aliphatic polyethers obtained from environmentally benign monomer: Glycerol carbonate. Green Chem. 2005, 7, 529-539. [CrossRef]

10. Algoufi, Y.T.; Hameed, B.H. Synthesis of glycerol carbonate by transesterification of glycerol with dimethyl carbonate over K-zeolite derived from coal fly ash. Fuel Process. Technol. 2014, 126, 5-11. [CrossRef]

11. Aresta, M.; Dibenedetto, A.; Nocito, F.; Pastore, C. A study on the carboxylation of glycerol to glycerol carbonate with carbon dioxide: The role of the catalyst, solvent and reaction conditions. J. Mol. Catal. A Chem. 2006, 257, 149-153. [CrossRef]

12. Climent, M.J.; Corma, A.; De Frutos, P.; Iborra, S.; Noy, M.; Velty, A.; Concepción, P. Chemicals from biomass: Synthesis of glycerol carbonate by transesterification and carbonylation with urea with hydrotalcite catalysts. The role of acid-base pairs. J. Catal. 2010, 269, 140-149. [CrossRef]

13. Teng, W.K.; Ngoh, G.C.; Yusoff, R.; Aroua, M.K. Microwave-assisted transesterification of industrial grade crude glycerol for the production of glycerol carbonate. Chem. Eng. J. 2016, 284, 469-477. [CrossRef]

14. Aresta, M.; Dibenedetto, A. Carbon dioxide fixation into organic compounds. In Carbon Dioxide Recovery and Utilization; Springer: Dordrecht, The Netherlands, 2003; pp. 211-260.

15. Nguyen, N.; Demirel, Y. Economic analysis of biodiesel and glycerol carbonate production plant by glycerolysis. J. Sustain. Bioenergy Syst. 2013, 3, 209. [CrossRef]

16. Sienel, G.; Rieth, R.; Rowbottom, K.T. Epoxides. In Ullmann's Encyclopedia of Industrial Chemistry; Wiley-VCH Verlag GmbH \& Co. KGaA: Weinheim, Germany, 2000; Volume A13, pp. 141-154.

17. Sonnati, M.O.; Amigoni, S.; de Givenchy, E.P.T.; Darmanin, T.; Choulet, O.; Guittard, F. Glycerol carbonate as a versatile building block for tomorrow: Synthesis, reactivity, properties and applications. Green Chem. 2013, 15, 283-306. [CrossRef]

18. Wang, D.; Zhang, X.; Liu, C.; Cheng, T. Synthesis of glycerol carbonate from glycerol and urea over lanthanum compounds. React. Kinet. Mech. Catal. 2015, 115, 597-609. [CrossRef]

19. Clegg, W.; Harrington, R.W.; North, M.; Pasquale, R. Cyclic carbonate synthesis catalysed by bimetallic aluminium-salen complexes. Chem.-A Eur. J. 2010, 16, 6828-6843. [CrossRef] [PubMed]

20. Gade, S.M.; Munshi, M.K.; Chherawalla, B.M.; Rane, V.H.; Kelkar, A.A. Synthesis of glycidol from glycerol and dimethyl carbonate using ionic liquid as a catalyst. Catal. Commun. 2012, 27, 184-188. [CrossRef]

21. Meessen, J.H.; Petersen, H. Urea. In Ulmann's Encyclopedia of Industrial Chemistry; Wiley-VCH Verlag GmbH \& Co. KGaA: Weinheim, Germany, 2000; Volume A27, pp. 333-350.

22. Undri, A.; Frediani, M.; Rosi, L.; Frediani, P. Reverse polymerization of waste polystyrene through microwave assisted pyrolysis. J. Anal. Appl. Pyrolysis 2014, 105, 35-42. [CrossRef]

23. Shukla, K.; Srivastava, V.C. Synthesis of organic carbonates from alcoholysis of urea: A review. Catal. Rev. 2017, 59, 1-43. [CrossRef]

24. Fernandes, G.P.; Yadav, G.D. Selective glycerolysis of urea to glycerol carbonate using combustion synthesized magnesium oxide as catalyst. Catal. Today 2017, 309, 153-160. [CrossRef]

25. Li, Q.; Zhang, W.; Zhao, N.; Wei, W.; Sun, Y. Synthesis of cyclic carbonates from urea and diols over metal oxides. Catal. Today 2006, 115, 111-116. [CrossRef]

26. Mohedano, A.; Monsalvo, V.; Bedia, J.; Lopez, J.; Rodriguez, J. Highly stable iron catalysts from sewage sludge for cwpo. J. Environ. Chem. Eng. 2014, 2, 2359-2364. [CrossRef]

27. Bedia, J.; Monsalvo, V.; Rodriguez, J.; Mohedano, A. Iron catalysts by chemical activation of sewage sludge with $\mathrm{FeCl}_{3}$ for CWPO. Chem. Eng. J. 2017, 318, 224-230. [CrossRef]

28. Arnold, R.A.; Habibi, R.; Kopyscinski, J.; Hill, J.M. Interaction of potassium and calcium in the catalytic gasification of biosolids and switchgrass. Energy Fuels 2017, 31, 6240-6247. [CrossRef] 
29. Liu, Z.; McNamara, P.; Zitomer, D. Biochar production and bio-oil upgrading by synergistic catalytic pyrolysis of wastewater biosolids and industrial wastes. Proc. Water Environ. Fed. 2016, 2016, 3182-3187. [CrossRef]

30. Tu, Y.; Xiong, Y.; Tian, S.; Kong, L.; Descorme, C. Catalytic wet air oxidation of 2-chlorophenol over sewage sludge-derived carbon-based catalysts. J. Hazard. Mater. 2014, 276, 88-96. [CrossRef] [PubMed]

31. Chae, M.; Xia, L.; Zhu, C.; Bressler, D.C. Accelerating settling rates of biosolids lagoons through thermal hydrolysis. J. Environ. Manag. 2018, 220, 227-232. [CrossRef] [PubMed]

32. Aresta, M.; Dibenedetto, A.; Nocito, F.; Ferragina, C. Valorization of bio-glycerol: New catalytic materials for the synthesis of glycerol carbonate via glycerolysis of urea. J. Catal. 2009, 268, 106-114. [CrossRef]

33. Aresta, M.; Dibenedetto, A.; Quaranta, E. Reaction mechanisms in the direct carboxylation of alcohols, polyols, cyclic ethers, and cyclic amines to afford monomeric compounds and polymeric materials. In Reaction Mechanisms in Carbon Dioxide Conversion; Springer: Berlin/Heidelberg, Germany, 2016; pp. 183-235.

34. Suyatmo, R.I.D.; Sulistyo, H.; Sediawan, W.B. The synthesis of glycerol carbonate from biodiesel by product glycerol and urea over amberlyst 15. Jurnal Bahan Alam Terbarukan 2017, 6, 1-5.

35. Lertlukkanasuk, N.; Phiyanalinmat, S.; Kiatkittipong, W.; Arpornwichanop, A.; Aiouache, F.; Assabumrungrat, S. Reactive distillation for synthesis of glycerol carbonate via glycerolysis of urea. Chem. Eng. Process. Process Intensif. 2013, 70, 103-109. [CrossRef]

36. Park, J.-H.; Choi, J.S.; Woo, S.K.; Lee, S.D.; Cheong, M.; Kim, H.S.; Lee, H. Isolation and characterization of intermediate catalytic species in the Zn-catalyzed glycerolysis of urea. Appl. Catal. A Gen. 2012, 433, 35-40. [CrossRef]

37. Rubio-Marcos, F.; Calvino-Casilda, V.; Bañares, M.A.; Fernandez, J.F. Control of the interphases formation degree in $\mathrm{Co}_{3} \mathrm{O}_{4} / \mathrm{ZnO}$ catalysts. ChemCatChem 2013, 5, 1431-1440. [CrossRef]

38. Manjunathan, P.; Ravishankar, R.; Shanbhag, G.V. Novel bifunctional Zn-Sn composite oxide catalyst for the selective synthesis of glycerol carbonate by carbonylation of glycerol with urea. ChemCatChem 2016, 8 , 631-639. [CrossRef]

39. Ab Rahim, M.H.; He, Q.; Lopez-Sanchez, J.A.; Hammond, C.; Dimitratos, N.; Sankar, M.; Carley, A.F.; Kiely, C.J.; Knight, D.W.; Hutchings, G.J. Gold, palladium and gold-palladium supported nanoparticles for the synthesis of glycerol carbonate from glycerol and urea. Catal. Sci. Technol. 2012, 2, 1914-1924. [CrossRef]

40. Kim, D.-W.; Park, M.-S.; Selvaraj, M.; Park, G.-A.; Lee, S.-D.; Park, D.-W. Catalytic performance of polymer-supported ionic liquids in the synthesis of glycerol carbonate from glycerol and urea. Res. Chem. Intermed. 2011, 37, 1305. [CrossRef]

41. Wang, L.; Ma, Y.; Wang, Y.; Liu, S.; Deng, Y. Efficient synthesis of glycerol carbonate from glycerol and urea with lanthanum oxide as a solid base catalyst. Catal. Commun. 2011, 12, 1458-1462. [CrossRef]

42. Omidghane, M.; Jenab, E.; Chae, M.; Bressler, D.C. Production of renewable hydrocarbons by thermal cracking of oleic acid in the presence of water. Energy Fuels 2017, 31, 9446-9454. [CrossRef]

43. Benitez, E.; Romero, E.; Gomez, M.; Gallardo-Lara, F.; Nogales, R. Biosolids and biosolids-ash as sources of heavy metals in a plant-soil system. Water Air Soil Pollut. 2001, 132, 75-87. [CrossRef]

44. Boehm, H.P. Acidic and basic properties of hydroxylated metal oxide surfaces. Discuss. Faraday Soc. 1971, 52, 264-275. [CrossRef]

(C) 2018 by the authors. Licensee MDPI, Basel, Switzerland. This article is an open access article distributed under the terms and conditions of the Creative Commons Attribution (CC BY) license (http://creativecommons.org/licenses/by/4.0/). 